\title{
A Contrast of U.S. Metropolitan Demographic Poverty: Chicago, Los Angeles, and New York
}

\author{
Robert G. Mogull \\ College of Business Administration, California State University at Sacramento, Sacramento, CA 95819, USA \\ Correspondence should be addressed to Robert G. Mogull, mogullr@csus.edu \\ Received 20 June 2011; Accepted 28 July 2011 \\ Academic Editor: Peter J. Congdon \\ Copyright () 2011 Robert G. Mogull. This is an open access article distributed under the Creative Commons Attribution License, \\ which permits unrestricted use, distribution, and reproduction in any medium, provided the original work is properly cited. \\ This paper examines and compares U.S. poverty rates on two levels, with data obtained from the decennial censuses of 1960 \\ through 2000. First, rates of poverty for five demographic groups are contrasted within each of the three most populous \\ metropolises of the nation-Chicago, Los Angeles/Long Beach, and New York. Second, rates for each demographic group are \\ contrasted among the three metropolises. The statistical evidence reveals both large differences among the individual demographic \\ groups and also in the trends among the three most populous American cities.
}

\section{Goals}

The goal of this study is to reveal substate differences and patterns in demographic poverty. In this paper, three major U.S. metropolises are contrasted-consisting of Chicago, Los Angeles/Long Beach, and New York City. The three metropolises are geographically dispersed across the nation, and each is a primary destination for new immigrants. They offer both employment opportunities and significant public and private social support services that, in themselves, perhaps serve as attractions or magnets to the recent arrivals. The demographic groups to be included and contrasted consist of All Residents, Asians and Pacific Islanders, Blacks, Hispanics, and Whites. These subgroups account for the bulk of the impoverished population within each metropolitan area.

\section{Poverty Definition}

The definition of poverty, that is employed by the Census Bureau and that is used in this paper, was originally developed in 1964 by Mollie Orshansky of the Social Security Administration [1]. Income levels for delineating the poor are determined by the cost of a low-income nutritionally adequate food plan called an Economy Food Plan. The plan was based upon a Household Food Consumption Survey conducted in 1955 by the U.S. Department of Agriculture.
In that survey, it was found that families of three or more persons across all income levels spent roughly one-third of after-tax income on food. Consequently, the cost of a subsistence food plan was multiplied by three in order to obtain the poverty thresholds. The other two-thirds of income were presumed to be used to cover minimal needs for clothing, shelter, and other living essentials. Specific thresholds were established for families of varying size and composition - that is, for the number of adults and children as well as for the age of the family head. In the 2000 decennial census, for example, the Bureau used 48 separate thresholds for determining poverty levels of families and unrelated individuals.

Poverty indexes are determined by pretax money income only and are adjusted annually for changes in the national cost of living, as reflected by the Consumer Price Index for urban dwellers. The official poverty threshold for a family of four, for example, has grown from \$2,973 in 1959 to $\$ 22,314$ (preliminary) in 2010. However, the indexes and thresholds are not adjusted for regional differences in living costs. Consequently, since the cost of living in the Chicago metropolitan area is $18 \%$ greater than the national average for all urban areas, 23\% greater in Los Angeles/Long Beach, and $140 \%$ greater in New York City, poverty is substantially underestimated in each of the three most populous urban centers [2]. 
TABLe 1: Poverty rates SMSA: 1959, 1969, 1979; PMSA: 1989, 1999.

\begin{tabular}{|c|c|c|c|c|c|}
\hline Year & All Residents & Asian and Pacific Islander & Black & Hispanic & White \\
\hline \multicolumn{6}{|c|}{ Chicago } \\
\hline 1959 & 11.7 & $\mathrm{n} / \mathrm{a}$ & 35.0 & $\mathrm{n} / \mathrm{a}$ & 7.6 \\
\hline 1969 & 9.3 & $\mathrm{n} / \mathrm{a}$ & 24.3 & 14.7 & 6.0 \\
\hline 1979 & 11.3 & 8.9 & 29.5 & 20.6 & 5.8 \\
\hline 1989 & 12.4 & 10.2 & 30.0 & 20.7 & 5.8 \\
\hline 1999 & 10.5 & 8.8 & 24.6 & 16.3 & 5.6 \\
\hline \multicolumn{6}{|c|}{ Los Angeles/Long Beach } \\
\hline 1959 & 13.0 & $\mathrm{n} / \mathrm{a}$ & 28.3 & $\mathrm{n} / \mathrm{a}$ & 11.4 \\
\hline 1969 & 10.9 & $\mathrm{n} / \mathrm{a}$ & 23.9 & 14.2 & 9.2 \\
\hline 1979 & 13.4 & 12.8 & 23.1 & 20.5 & 9.9 \\
\hline 1989 & 15.1 & 13.2 & 21.2 & 22.9 & 10.6 \\
\hline 1999 & 17.9 & 13.9 & 24.4 & 24.2 & 13.4 \\
\hline \multicolumn{6}{|c|}{ New York City } \\
\hline 1959 & 13.8 & $\mathrm{n} / \mathrm{a}$ & 30.9 & $\mathrm{n} / \mathrm{a}$ & 11.5 \\
\hline 1969 & 11.9 & $\mathrm{n} / \mathrm{a}$ & 23.6 & 34.4 & 9.5 \\
\hline 1979 & 16.8 & 13.3 & 28.6 & 34.5 & 10.4 \\
\hline 1989 & 17.5 & 15.2 & 24.8 & 32.3 & 10.8 \\
\hline 1999 & 19.5 & 18.7 & 25.1 & 29.8 & 13.1 \\
\hline
\end{tabular}

$\mathrm{n} / \mathrm{a}$ : statistic is not available.

Source: [4].

Counts and incidences of U.S. poverty are constructed from definitions and procedures adopted by the Bureau of the Census. These official estimates are universally employed by governmental agencies at all jurisdictional levels and have been used consistently since their original development by the Social Security Administration. In 1969, the Bureau of the Budget (now the Office of Management and Budget) formally prescribed the poverty thresholds as the official standard to be used by all federal agencies.

Yet, the estimates have been criticized and been modified over the years by several federal interagency committees. Some major points of criticism that still remain include that noncash benefits (such as food stamps, school lunches, health benefits, subsidized housing, income-in-kind, and deferred benefits) as well as assets are excluded from the determination of poverty status; either median income or disposable income would be a more appropriate benchmark for poverty; money income is underreported by recipients; interhousehold transfers are unreliably estimated; intrahousehold transfers are ignored; poor Blacks, Hispanics, and the homeless are particularly undercounted; the mix and cost of a nutritionally adequate diet needs to be updated.

Nevertheless, as stated by Wendell Primus, "The real importance of a ... poverty measure is not the [true] number who is poor in any one year but the indicator's ability to show whether the number is decreasing or increasing over time" [3]. Despite modifications and numerous criticisms, it appears that the Census Bureau will continue to use the present definition of U.S. poverty and its methods of tabulation for the foreseeable future.

\section{The Data}

In order to trace and analyze metropolitan poverty in this study, decennial censuses conducted by the U.S. Bureau of the Census provide the necessary statistical benchmarks on poverty rates (that is, on the incidences of poverty). The three metropolitan areas contrasted accounted for $12.7 \%$ of the nation's 33.9 million total impoverished persons in 1999 (the latest year of available decennial census poverty data). The three cities encompassed $26.5 \%$ of the nation's total impoverished Asians and Pacific Islanders, $14 \%$ of Blacks, $24.7 \%$ of Hispanics, and $7.9 \%$ of Whites. Yet, as mentioned, due to the much higher living costs in urban areas, these percentages are extremely conservative.

Incidences of poverty (that is, of rates of poverty) for each group rather than poverty counts are compared. Rates of poverty indicate the hardship or the burden that is borne internally by each demographic segment. In contrast, group poverty counts indicate the relative burdens upon the municipalities. These comparative burdens are traced over all currently available benchmark years of data-1959, 1969, 1979,1989 , and 1999. Table 1 presents the universe of poverty rates by metropolis and by demographic group. The table and all figures are created by the author of this paper, based upon the official data provided by the Bureau.

\section{The Evidence}

An examination of Table 1 and of Figures 1,2 and 3 indicates that for All Residents, the incidence (i.e., rate) of overall poverty has shown the greatest stability within 


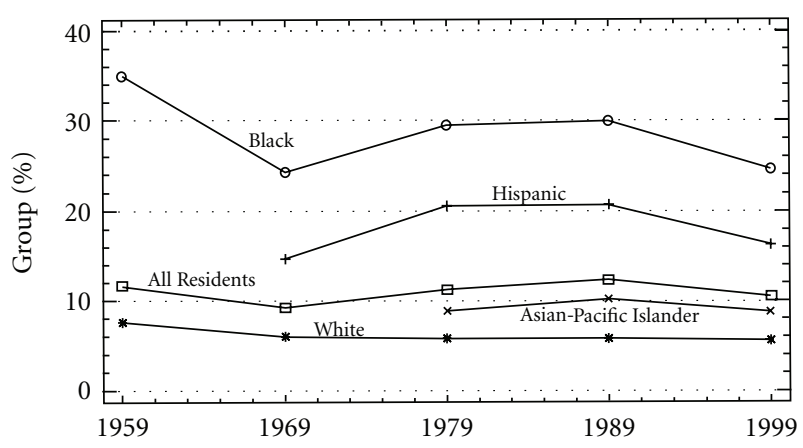

Figure 1: Chicago poverty rates. Source: [4].

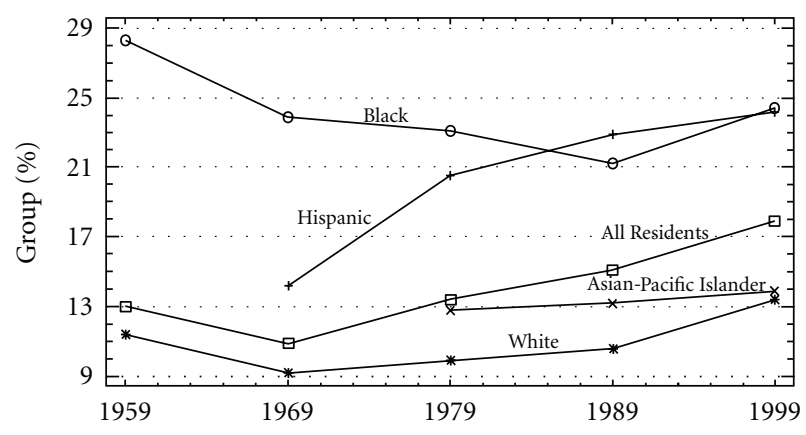

Figure 2: Los Angeles/Long Beach poverty rates. Source: [4].

Chicago-ranging between $9.3 \%$ and $12.4 \%$ over 40 years and with no clear trend. Since 1969, both Los Angeles/Long Beach (LA/LB) and New York City (NYC) have experienced constantly increasing overall poverty rates. In $\mathrm{LA} / \mathrm{LB}$, the aggregate rate has reached $17.9 \%$, while in NYC it reached $19.5 \%$. In all three metropolitan regions, rates of poverty for Blacks and for Hispanics consistently far exceeded the rates for other racial groups as well as for All Residents. There are contrasts within the metropolises, however, in the specific patterns for Blacks and for Hispanics. Although the Black and Hispanic rates have followed roughly parallel paths over time in Chicago, in LA/LB the paths for the two groups are especially dissimilar. Whereas Black poverty rates in LA/LB appear to have declined, Hispanic rates have grown. In NYC, paths for both groups have been falling, but more consistently for Hispanics than for Blacks. Paths for Asians and Pacific Islanders and for Whites, although dissimilar, are traditionally the lowest among all racial groups as well as below the overall rates. Since 1969, the path for White rates in LA/LB has severely ratcheted up from $9.2 \%$ to $13.4 \%$. In NYC, White rates since 1969 have also risen strongly from 9.5\% to $13.1 \%$. Poverty rates for Asians and Pacific Islanders in NYC, however, experienced particularly large jumps from $13.3 \%$ to $18.7 \%$ over only 20 years.

With respect to the aggregate rate of poverty among All Residents, the difference between the third most populous metropolis and the other two is striking (Table 1, Figure 4). In 1959, the three cities began with relatively narrow differences but, over time, have increasingly diverged. NYC has consistently maintained the highest overall rates

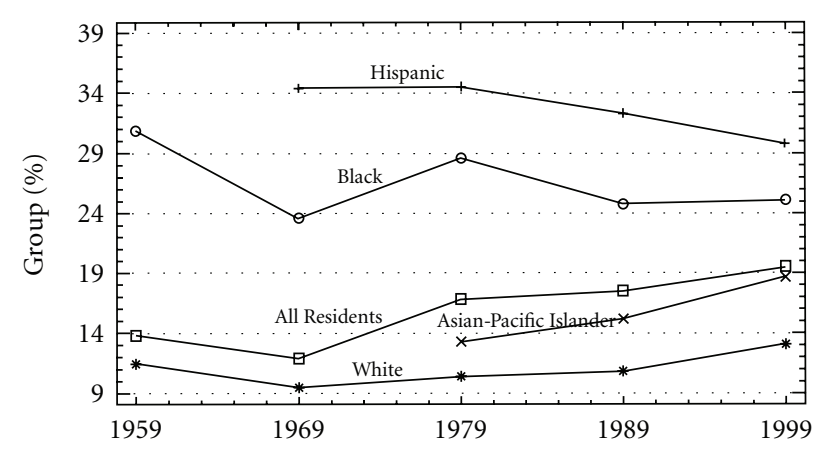

FIgURE 3: New York City poverty rates. Source: [4].

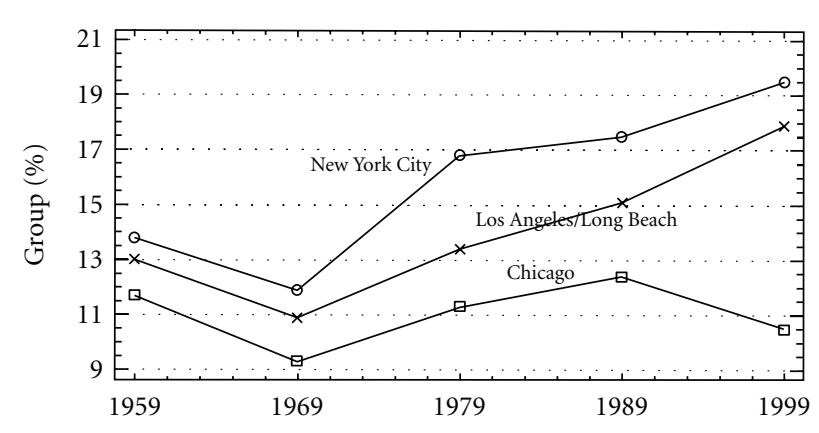

FIGURE 4: All Residents three city poverty rates. Source: [4].

(15.9\% average), while LA/LB followed (14.06\% average). Chicago has also been consistent-but in retaining the lowest aggregate rates among the three cities (11.04\% average). Whereas rates in both NYC and LA/LB have risen markedly, Chicago's temporal rates have fluctuated within a comparatively narrow band of only 3.1 points over four decades. The difference between NYC and Chicago has widened nearly consistently from 2.1 points in 1959 to 9 points in 1999.

Among Asians and Pacific Islanders (A\&PI), poverty rates have similarly diverged over time between the highest $(15.7 \%$ average in NYC) and the lowest (9.3\% average in Chicago) (see Table 1, Figure 5). Rates in LA/LB have trended upwards (by 1.1 points), but not as abruptly and explosively as in NYC (5.4 points over just 20 years). The spread in rates between the highest and lowest cities has widened greatly, with the differential between NYC and Chicago more than doubling-from 4.4 points in 1979 to 9.9 in 1999. (Asians alone comprised $97.8 \%$ of the combined impoverished A\&PI category among all three cities in 1999. That is, the joint category of A\&PI consists almost exclusively of Asians.)

Black poverty rates within the three locales appear to trend downwards in each case (Table 1, Figure 6). This is based upon the paths observed between 1959 and 1999. However, Black rates in 1959 must be tempered by the knowledge that they are not composed solely of Blacks. In 1959, Black rates consisted both of Blacks and of all other races except Whites - that is, it encompassed all nonwhite persons. Thus, although the 1959 rates for Blacks were at historical highs, they must be viewed with caution. For Blacks, Chicago atypically lies above the other two 


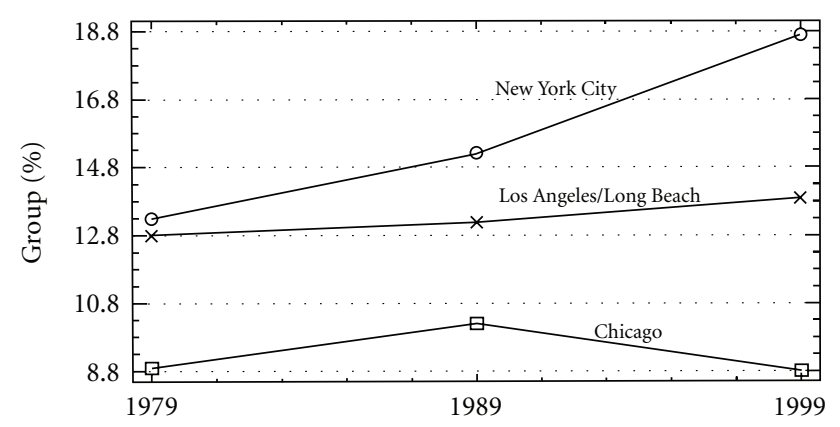

Figure 5: Asian \& Pacific Islander three city poverty rates. Source: [4].

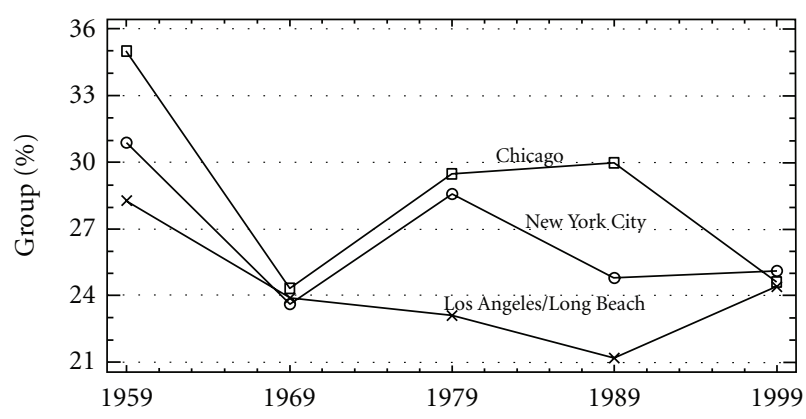

FIGURE 6: Black three city poverty rates. Source: [4].

municipalities. Average temporal Black poverty in Chicago usually is higher $(28.7 \%)$ than found in LA/LB $(24.2 \%)$ or in NYC (26.6\%). By 1999, however, this arrangement shifted. In the most recent decennial census, there was very little difference among the three cities-when all three exhibited a Black poverty incidence of about $25 \%$.

NYC maintains the highest poverty rates for Hispanics with a $32.8 \%$ average-compared to an average of $18.1 \%$ in Chicago and $20.5 \%$ in LA/LB (Table 1, Figure 7). In recent decades, both NYC and Chicago have experienced declining Hispanic rates. Yet, LA/LB has seen continuous but tapering decade increases of $44 \%, 12 \%$, and $6 \%$. Once again, there are several qualifications to be noted regarding the official statistics. First, the NYC Hispanic poverty rate for 1969 represents "Persons of Puerto Rican birth or parentage" only-that is, not of all Hispanic ethnicities. Second, the 1969 Hispanic classification is defined differently than in latter census years. The 1969 classification (in Chicago and in LA/LB) includes "Persons of Spanish language or Spanish surname," while the more recent decennial censuses use the Hispanic ethnicity criterion. Thus, according to the Census Bureau, official statistics for 1969 and for latter years are not entirely comparable. The Hispanic designation is a cultural, ethnic, or heritage description and, thus, Hispanics may be of any race.

Among Whites, NYC and LA/LB have followed nearly identical paths since 1959 (Table 1, Figure 8). Their trends over the past three decades are explosive (4.2 point rise in LA/LB and 3.6 point rise in NYC) and the temporal differences between the two metropolises are minor. Chicago's

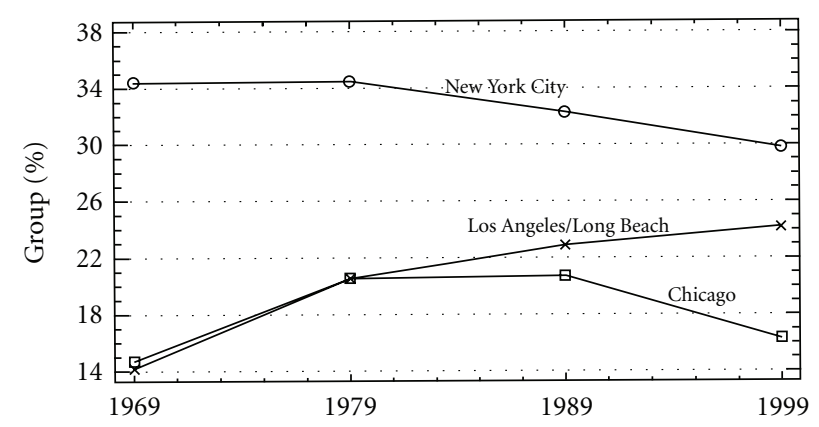

FIGURE 7: Hispanic three city poverty rates. Source: [4].

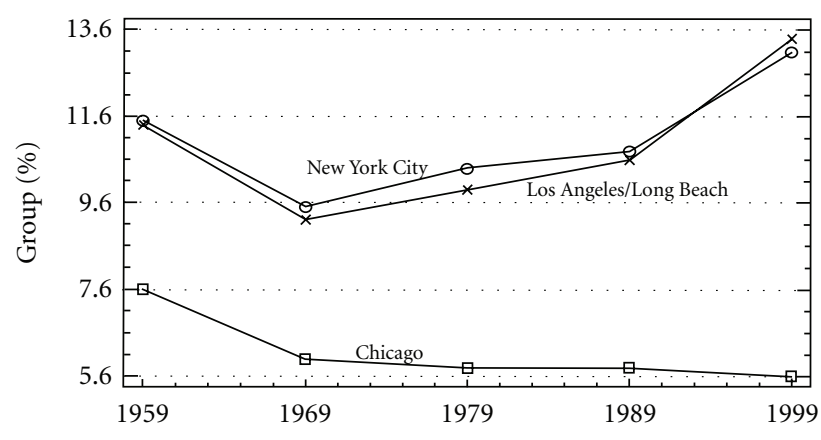

FIgURE 8: White three city poverty rates. Source: [4].

poverty rates for Whites have shown a continuous decline from $7.6 \%$ to $5.6 \%$ over 40 years and the differential between Chicago and either NYC or LA/LB expanded to over 7 points by 1999. The White poverty rate in Chicago appears to have leveled off at the mid-five percent range.

\section{Summary and the Next Steps}

This paper examined and compared historical poverty rates on two levels. First, rates for five demographic groups are contrasted within each of the three most populous metropolises in the U.S.-Chicago, Los Angeles/Long Beach, and New York City. Second, temporal rates for each separate demographic group were contrasted among the three cities. The historical framework consisted of the universe of decennial census poverty dates of 1959 through 1999which are derived from the corresponding national decennial censuses of 1960 through 2000.

The evidence indicates that within every metropolitan area, Black and Hispanic rates far exceed the overall rates for All Residents as well as for Whites and for Asians and Pacific Islanders. NYC typically surpasses both LA/LB and Chicago in most demographic poverty categories, while Chicago's categorical rates generally have been far below the other two cities. The exception is Blacks where, until most recently, Chicago's rates exceeded the other metropolitan areas. Currently, the Black poverty incidence is about the same in all three cities.

Aggregate poverty rates in both NYC and LA/LB are strongly trending up, while those in Chicago have fluctuated 
narrowly. The incidence of poverty among Asians and Pacific Islanders has risen especially in NYC. Black poverty has recently increased in LA/LB but has fallen in Chicago. Hispanic rates are rising in LA/LB only-but by sharply diminishing increments. White poverty rates reveal explosive patterns both in NYC and in LA/LB over the past three decades.

This study is descriptive. It was not the purpose of this paper to attempt to provide explanations. However, it is appropriate to now consider the causes or the factors that influence the levels, trends, and divergences among the observed metropolitan rates. Overall poverty levels and trends differ among the cities as well as between demographic subpopulations within the cities. To further complicate the picture, we see variations for each individual group among the three major metropolises. Additional studies should pick apart this evidence to identify the specific causes/factors which underlie the evidence.

There can be a wide variety of economic, social, psychological, and chance influences on the levels, trends, and divergences of the rates of poverty. Further, exogenous common factors may likely have affected the individual demographic groups in distinct ways. For example, a period of economic contraction does not provide a blanket of uniform hardship upon all subgroups. Ultimately, the end goal is to prevent and counteract those factors which cause poverty. The factors are likely to have time, location, and group specific influences. This paper presents a very limited although necessary initial step.

\section{References}

[1] M. Orshansky, "How poverty is measured," Monthly Labor Review, vol. 92, pp. 37-41, 1969.

[2] Bureau of the Census, U.S. Department of Commerce, Statistical Abstract of the United States: 2000 (120th Edition), Washington, DC, USA, Table 771, pp. 490-491, 2000.

[3] W. Primus, "Comments," Focus, vol. 17, no. 1, p. 27, 1995.

[4] Bureau of the Census, U.S. Department of Commerce, Washington, DC, USA, http://www.census.gov/hhes/www/poverty .html. 


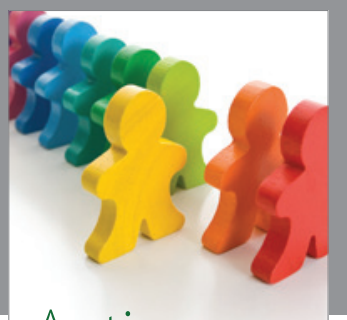

Autism

Research and Treatment
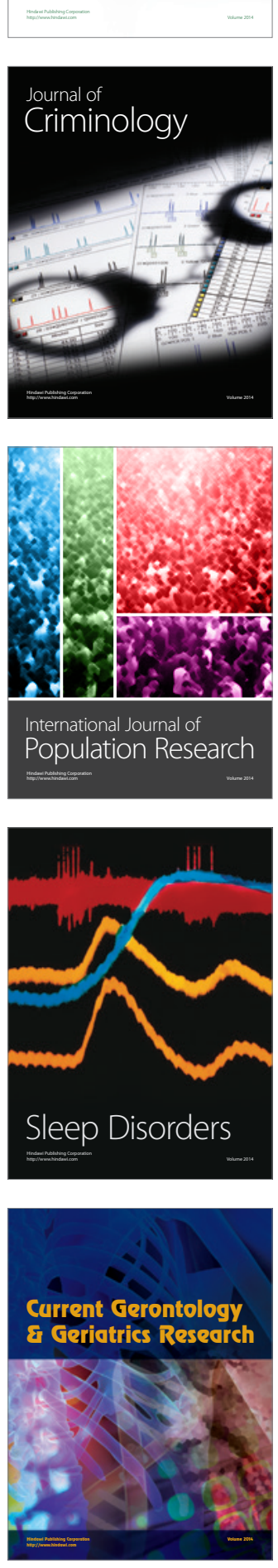
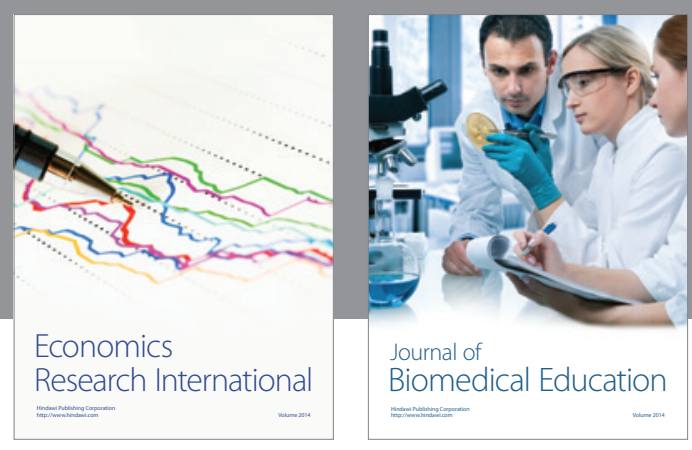

Journal of

Biomedical Education

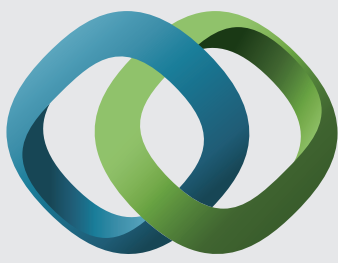

\section{Hindawi}

Submit your manuscripts at

http://www.hindawi.com
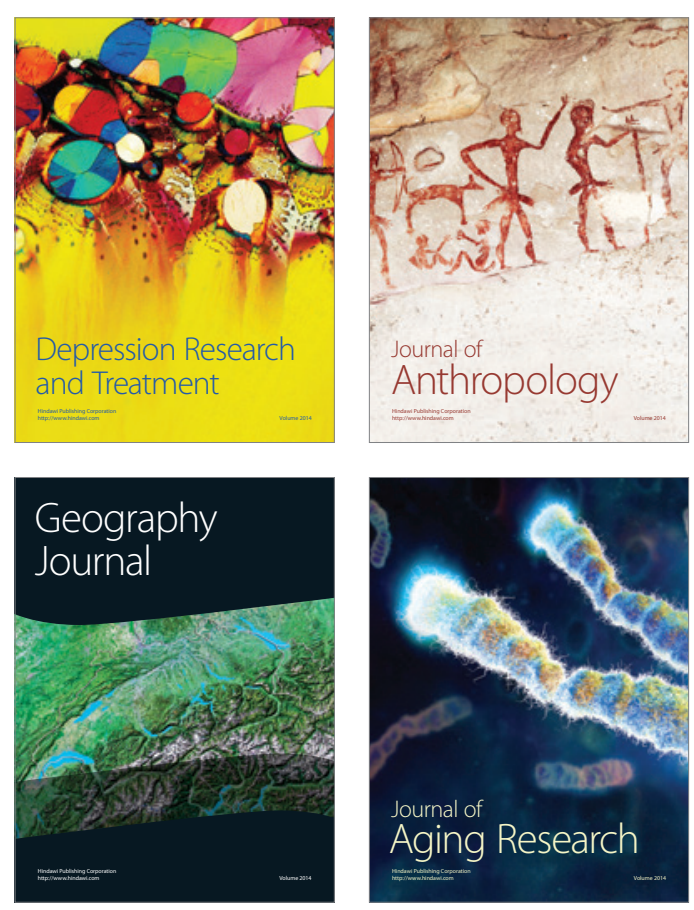

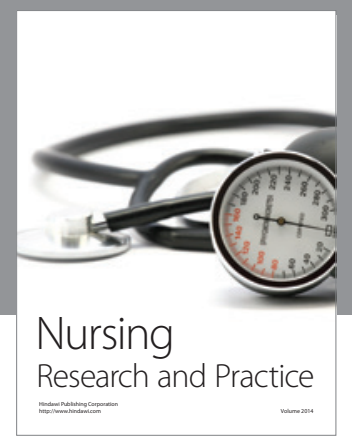

Nursing

Research and Practice

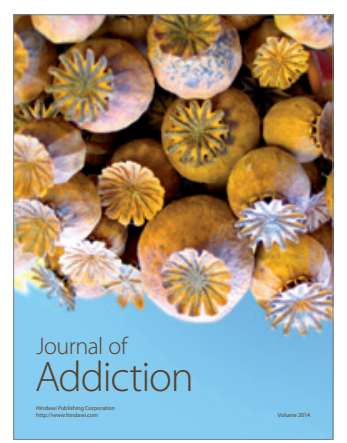

Child Development

Research

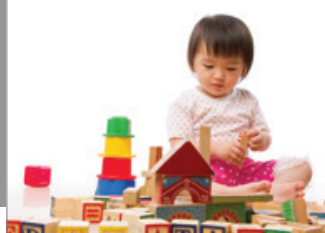

迥
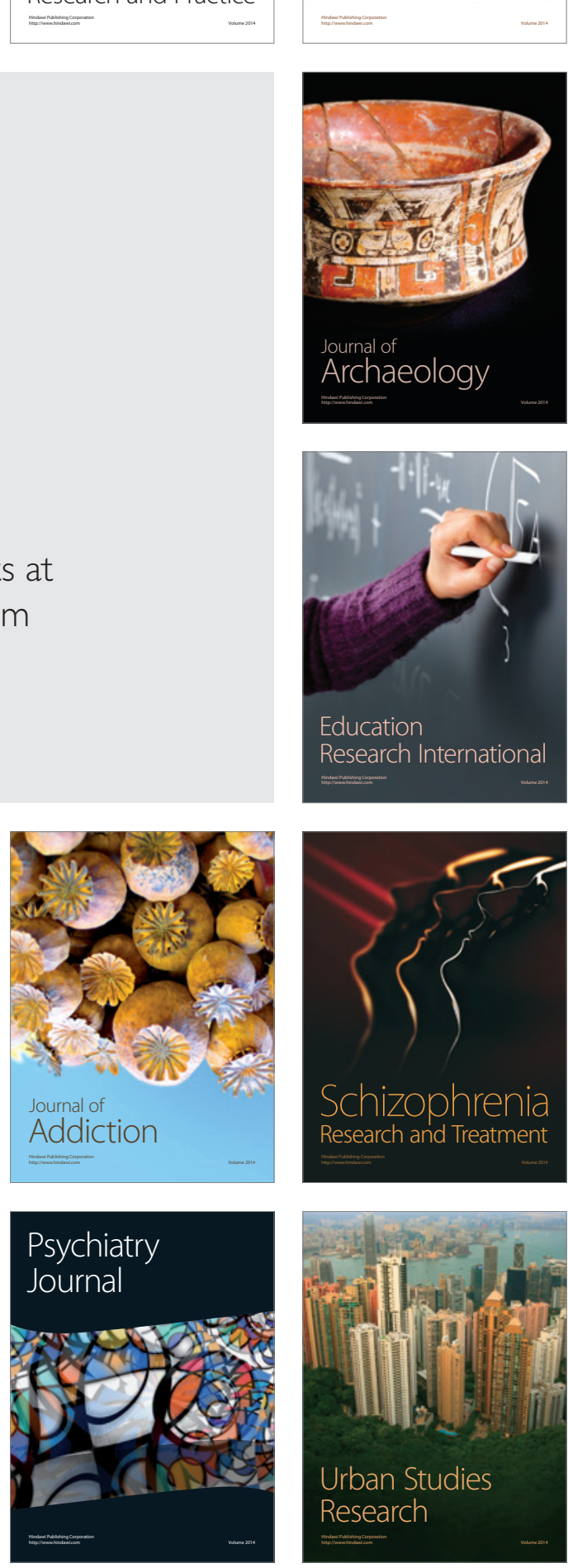